Published in final edited form as:

Nat Rev Gastroenterol Hepatol. ; 9(6): 334-344. doi:10.1038/nrgastro.2012.63.

\title{
MicroRNAs in pancreatic cancer metabolism
}

\author{
Pankaj K. Singh, Randall E. Brand, and Kamiya Mehla \\ The Eppley Institute for Cancer and Allied Diseases, University of Nebraska Medical Center, \\ 987696 Nebraska Medical Center, Omaha, Nebraska, 68198, USA (P. K. Singh, K. Mehla). \\ Division of Gastroenterology, Hepatology and Nutrition, PUH, M2, C Wing - 200 Lothrop St., \\ University of Pittsburgh, PA 15213, USA (R. E. Brand)
}

\begin{abstract}
Advances in understanding the biology of tumour progression and metastasis have clearly highlighted the importance of aberrant tumour metabolism, which supports not only the energy requirements but also the enormous biosynthetic needs of tumour cells. Such metabolic alterations modulate glucose, amino acid and fatty-acid-dependent metabolite bio-synthesis and energy production. Although much progress has been made in understanding the somatic mutations and expression genomics behind these alterations, the regulation of these processes by microRNAs (miRNAs) is only beginning to be appreciated. This Review focuses on the miRNAs that are potential regulators of the expression of genes whose protein products either directly regulate metabolic machinery or serve as master regulators, indirectly modulating the expression of metabolic enzymes. We focus particularly on miRNAs in pancreatic cancer.
\end{abstract}

\section{Introduction}

Pancreatic cancer is the fourth leading cause of cancer-related deaths, with a 5-year survival rate of $6 \% .{ }^{1}$ It is characterized by an extremely aggressive tumour growth rate and a high incidence of metastasis. The poor prognosis of this malignancy reflects late diagnosis and poor response to the current standard of care (gemcitabine). Thus, in order to devise better diagnostics and therapeutics for pancreatic cancer, an urgent need exists to understand the biology of the disease at a molecular level. As with most other epithelial-cell-derived cancers, pancreatic cancer initiation and progression involves multiple signalling networks that alter the balance from controlled cell growth to uncontrolled proliferation and metastatic potential.

From a metabolic standpoint, most of these signalling networks act to alter the energy profile of cancer cells and enhance the production of biosynthetic intermediates, which are required for generating the building blocks to sustain growth and survival in unfavourable microenvironments. Aberrant expression and activity of metabolic enzymes is one of the hallmarks of cancer. These metabolic alterations are only just beginning to be understood in

Correspondence to: P. K. Singh pankaj.singh@unmc.edu.

Author contributions: PK Singh and K Mehla researched data for the article. All authors contributed to discussions of content, writing, reviewing and editing the manuscript.

Competing interests: The authors have declared that no competing interests exist. 
pancreatic cancer, and have vast implications for diagnosis and therapy. Alterations in the expression of glucose transporters (for example GLUT-1) have been linked with disease prognosis and staging. ${ }^{2}$ Polymorphisms or mutations in genes involved in glucose metabolism are also important predictors of overall survival of patients with pancreatic cancer. ${ }^{3}$ Several key pathways, including K-ras, hypoxia-inducible factor 1-alpha (HIF1a), p53 and mammalian target of rapamycin (mTOR), that regulate the expression and activities of metabolic enzymes are altered in pancreatic cancer. ${ }^{4-6}{ }^{18}$ F-labeled fluorodeoxyglucose (FDG)-based PET imaging is successfully being used to diagnose the presence and size of pancreatic tumours, indicating that increased glucose uptake and metabolism is a prominent feature in pancreatic cancer. ${ }^{7,8}$

miRNAs are noncoding RNAs that are 18 to 25 nucleotides long. They regulate gene expression via complementarity with the $3^{\prime}$-untranslated region (3'-UTR) of their target mRNAs. miRNAs regulate gene expression either by target mRNA degradation, repression of its translation or sometimes by upregulation of the target gene. The expression of the vast majority of oncogenes and tumour suppressors is fine-tuned by miRNAs in response to a variety of extracellular cues. ${ }^{9-11}$ Evidence indicates that cancers of multiple origins owe their pathogenesis to altered miRNA regulation. ${ }^{12,13}$ miRNAs directly or indirectly regulate several key enzymes and/or signalling hubs that cause alterations in metabolic pathways, resulting in tumour progression and/or metastasis. The field of miRNA-mediated metabolic regulations is only beginning to unfold and is opening new dimensions for cancer researchers. In this Review we present a comprehensive summary of miRNA-mediated metabolic regulation in cancer, with a special emphasis on pancreatic cancer (Table 1).

\section{Metabolic activity regulating miRNAs}

As evident from a plethora of studies, miRNAs regulate a number of physiological processes, including hematopoiesis, stem cell differentiation, adipocyte differentiation and insulin secretion. ${ }^{12-13}$ Furthermore, involvement of miRNAs in cancer, diabetes and other metabolic diseases has been described extensively ${ }^{12}$. It is important to note that the regulation of metabolism by miRNAs is not a one-way road; metabolic alterations in the extracellular milieu also tend to regulate miRNA expression and activity. Cellular stimuli as diverse as oxidative stress, glucose level and hypoxia, critically orchestrate miRNA activity in various pathologies, including pancreatic cancer. ${ }^{14-17}$ Such alterations in miRNA function add an extra level of complexity in understanding the metabolic regulation of cancer by miRNAs.

\section{Oxidative stress}

Oxidative stress via generation of reactive oxygen species (ROS) is a key characteristic of tumour cells. ROS control tumour growth by modulating proliferation, apoptosis and senescence through oncogenic stimuli. ${ }^{18}$ Mitochondria-deficient cancer cells that generate fewer ROS exhibit poor anchorage-independent growth compared with normal counterparts. ${ }^{19}$ Be sides regulating tumour growth, ROS also have a crucial role in cancer metabolism. Under various cues from the tumour microenvironment that facilitate ROS production, ROS triggers the activation of stress response genes including HIF1a, which subsequently activates pro-survival signals such as VEGF and GLUT-1. ${ }^{20,21}$ Intrigued by 
the diverse effects of ROS on tumour growth and development, researchers have investigated ROS-mediated regulation of miRNAs. The first evidence for the role of oxidative stress in controlling miRNA expression came from Simone et al., ${ }^{14}$ who identified induction of miRNA expression in human fibro-blasts by ionization-mediated oxidative stress. Similarly, ROS-producing agents such as tert-Butyl hydroperoxide increase the transcription of multiple miRNAs and lead to a corresponding reduction in their mRNA targets in auditory cells. ${ }^{22}$ ROS-responsive miR-155 and miR-7b are upregulated, whereas ROS-responsive miR-7c and miR-99a are downregulated in pancreatic cancer cell lines in contrast to their normal counterparts. ${ }^{23}$

\section{Hypoxia}

In association with oxidative stress, hypoxia (low oxygen tension) is a common characteristic feature of pancreatic tumours. Although low oxygen tension is assumed to kill normal cells, paradoxically, it promotes proliferation and survival of tumour cells. Evidence suggests that hypoxic conditions stimulate a number of transcription factors, such as HIF1a, NF- $\kappa \mathrm{B}$ and $\mathrm{p} 53$, that modulate tumour metabolism and enable tumour growth under harsh conditions. ${ }^{24}$ Hypoxic conditions also cause the upregulation of multiple miRNAs, including miR-21, 23a, 23b, 24, 26a, 26b, 27a, 30b, 93, 103, 103, 106a, 107, 125b, 181a, 181b, 181c, $192,195,210$ and $213 .{ }^{16,25}$ It is notable that miR-210, miR-181b, miR-23a and miR-23b are markers for pancreatic cancer as well. ${ }^{26,27}$ Interestingly, many of these miRNAs are involved in translating the metabolic effects that are signalled by HIF1a, c-myc and NF- $\kappa B$ in tumour cells. HIF-1-induced miR-210, which alters oxidative phosphorylation by targeting key components of the electron transport system, is a potential plasma biomarker for pancreatic cancer. ${ }^{28,29}$ Further more, hypoxic conditions can also cause the downregulation of certain miRNAs. ${ }^{25}$ Overexpression of miR-20a is implicated in a reduction in cellular proliferation and invasiveness of pancreatic cell lines. ${ }^{30}$

\section{Glucose status}

As with hypoxic conditions, glucose status also modulates miRNA levels in tumours. Hyper-glycemia is an important hallmark of pancreatic cancer, and it is due to hyperglycemia that patients with diabetes are more prone to developing pancreatic cancer. ${ }^{31}$ In pancreatic cancer, hyperglycemia is associated with increased invasiveness and motility of cancer cells. ${ }^{31}$ Crosstalk between glucose and miRNA is evident in the context of type 1 diabetes. The pancreatic islets of hyperglycemic GK (Goto-Kakizaki) rat, a genetic model of type II diabetes, demonstrate marked upregulation of miR-124, miR-212, miR-132, and miR-409-3p in contrast to the islets from normal GK mice. ${ }^{32}$ Similarly, high glucose treatment of pancreatic cell line MIN6 leads to upregulation of miR-30d, which causes insulin gene regulation in pancreatic $\beta$-cells. ${ }^{33}$

\section{Regulation of metabolic activity by miRNAs}

\section{Regulation of glucose uptake by miRNAs}

Glucose transporters (GLUT) are ubiquitous membrane proteins that facilitate sugar (glucose, fructose, galactose and xylose) uptake to meet the energy demands of growing and dividing cells. To date, 14 isoforms of GLUT have been identified, of which GLUT-1- 
GLUT-4 are well-characterized. ${ }^{34}$ In pancreatic carcinoma, GLUT-1 levels are known to be increased compared with GLUT-2 and GLUT-4 levels. ${ }^{35}$ Moreover, enhanced expression of GLUT-1 in these carcinomas drives invasion capacity (through induction of matrix metalloproteinase 2 [MMP2] $)^{36}$

Owing to the potential effect of GLUT on tumour development and metastasis, signalling mechanisms underlying their expression have been investigated. Regulation of GLUT receptor expression by hormones such as insulin, oestrogen, testosterone, glucocorticoids and thyroid hormones, is widely accepted. ${ }^{37-40}$ Reports also suggest that in most tumours, GLUT expression is under the influence of Ras, Src and c-Myc oncogenes. ${ }^{41,42}$ In addition, hypoxic and ischemic conditions, which are hallmarks of the tumour microenvironment, drive GLUT expression, ${ }^{43-45}$ and metabolic-stress-induced signalling pathways, such as AMPK, trigger upregulation of GLUT receptors. ${ }^{46}$ Given the role of miRNAs in regulating oncogene expression and their expression under hypoxic and/or ischemic conditions in tumours, their link with GLUT expression is not surprising.

A study in renal cell carcinoma demonstrated that miR199a, miR138, miR-150 and miR532-5p downregulate GLUT-1 whereas miR-130b, miR-19a/b and miR-301a increase GLUT-1 expression. ${ }^{47}$ Another group, while studying the role of miRNAs in type 2 diabetes, showed that miR-150 downregulates GLUT-4 levels in rat and human peripheral blood. ${ }^{48}$ Notably, miRNAs such as miR-301 and miR-130b are highly expressed in pancreatic tumours, and their role in regulating GLUT-1 expression might explain the increased glucose uptake that is observed in pancreatic adenocarcinoma. ${ }^{26,49}$ Similarly, reduced levels of miR-150, a negative regulator of GLUT-4 expression, have been reported in pancreatic cancer cells. ${ }^{50}$ Such alterations in the levels of miRNAs regulating GLUT-1 reflect a mechanism through which pancreatic tumours bypass regulatory checkpoints in GLUT-1 expression to suffice for the energy demands of rapidly dividing cells.

\section{Direct regulation of glycolysis by miRNAs}

miRNAs provide switches for the regulation of glycolysis, turning on and off in response to tumour needs (Figure 1). Studies show that miRNAs not only regulate the irreversible steps in glycolysis, but also other important intermediates of the pathway. For example, miR-122 and the miR-15a/16-1 cluster modulate glycolysis at steps other than the irreversible ones; ${ }^{51,52}$ miR-122 targets ALDOA, whereas the miR-15a/16-1 cluster reduces the level of ALDOA and TPI1, key enzymes in the glycolytic pathway. ${ }^{53,54}$ miR-122 is under the control of HIF1a and its loss correlates with increased invasion and migratory property of tumour cells in hepatocellular carcinoma. ${ }^{51,55}$ Similarly, the miR-15/16-1 cluster is known for its tumour suppressor activity both in vitro and in vivo. ${ }^{53}$ Thus, reduced levels of miR-122 and miR-15/16-1 might explain the high rates of glycolysis in tumour cells. miR-15a demonstrates cancer-suppressive functions in pancreatic cancer as well. ${ }^{56}$ Pancreatic cells that overexpress miR-15a demonstrate reduced viability compared with their normal counterparts. ${ }^{56}$ 


\section{Indirect regulation of glycolysis by miRNAs}

Regulation of growth factor signalling-Receptor tyrosine kinases (RTKs), such as epidermal growth factor receptor (EGFR) and platelet-derived growth factor receptor (PDGFR), and their corresponding ligands are expressed in a variety of tumours (including pancreatic cancer) and are implicated in cancer progression. ${ }^{57,58}$ Upon activation, RTKs regulate an array of signalling complexes, including ERK, PI3K/Akt, MAPK and phospholipase C; aberrant expression of RTKs can thus lead to the transformation, survival and growth of tumour cells. ${ }^{59,60}$ Aberrant expression/activation of RTKs is also linked with stabilization of HIF1a and activation of the mTOR pathway, which upregulates aerobic glycolysis, and regulation of PKM2 activity, a key glycolytic enzyme. ${ }^{61,62}$

Cross-regulation of miR-146a and EGFR signalling has been suggested in pancreatic cancer. ${ }^{63}$ miR-146a is expressed at low levels in pancreatic cancer and its upregulation diminishes cancer metastasis, partly by downregulating EGFR. In addition to regulating RTKs, miRNAs also regulate ligands; for example, in head and neck squamous cell carcinoma, an inverse relationship between heparin-binding EGF-like growth factor (HBEGF) and miR-212 has been reported. ${ }^{64}$ In these cells, reduced levels of miR-212 favour HB-EGF-derived cetuximab resistance. Similarly, in mast cells HB-EGF levels are regulated by miR-132. ${ }^{65}$ Both miR-212 and miR-132 are overexpressed in pancreatic cancer, in which HB-EGF might have a role in early phases of cancer progression. ${ }^{66,67}$

Regulation of p53 - p53, one of the most common tumour suppressor genes, guards against genomic insult, hence its description as the guardian angle gene. Besides protecting genomic DNA, p53 also modulates cellular metabolism by regulating glycolysis and oxidative phosphorylation. As evident from many studies, p53 exercises its control by inhibiting the expression of GLUT-1, GLUT-4 and phosphoglyceromutase (PGM), a glycolytic enzyme, or through TIGAR (TP53-induced glycolysis and apoptosis regulator protein that inhibits glycolytic enzyme PFKFB2)-expression-mediated inactivation of PFK1. ${ }^{68}$ Thus, p53 slows down the glycolysis rate to facilitate the pentose phosphate pathway that provides nucleotide precursors for the repair of damaged DNA. ${ }^{69}$ In parallel with glycolysis retardation, $\mathrm{p} 53$ drives oxidative phosphorylation by upregulating subunit I of cytochrome c oxidase and $\mathrm{SCO} 2{ }^{70,71}$ In addition, p53 is also involved in maintaining mitochondrial DNA stability. ${ }^{72}$

Some miRNAs are able to control p53 activity. As observed from microarray studies, p53regulating miRNAs are highly expressed in tumours and their levels are inversely related to p53 expression. In a report demonstrating the regulation of $\mathrm{p} 53$ by miRNAs, Le et al. ${ }^{73}$ identi fied miR-125b as a negative regulator of p53 in zebra fish.. Similar observations were made in human cells. ${ }^{73}$ Interestingly, another isoform of miR-125, miR-125a, targets p53 in kidney cells, where ectopic expression of miR-125a reduces p53 protein levels and rescues the cells from arsenic-induced apoptosis. ${ }^{74}$ Both of the isoforms of miR-125 are highly expressed in pancreatic cancer and are involved in tumorigenesis. ${ }^{27}$ Apart from the miR-125 family, several other miRNAs regulate the levels of p53 in normal and tumour cells, although they remain to be studied in the context of pancreatic cancer. 
Regulation of c-Myc-c-Myc is tightly regulated under normal conditions; however, it is aberrantly expressed in the majority of tumours. According to an estimate, deregulated expression of c-myc underlies 70,000 cancer-associated deaths per year in the USA. ${ }^{75} \mathrm{c}$ Myc is a transcription factor that regulates the expression of genes involved in nucleotide metabolism, DNA replication, and ribosomal and mitochondrial biogenesis. In addition, substantial experimental data support the crucial role of c-Myc in glutamine metabolism. ${ }^{76}$ Moreover, in concert with HIF1a, c-Myc regulates glucose uptake and glycolytic enzyme expression, thus favouring tumour growth in hostile environments. ${ }^{75}$

Given the relevance of c-Myc in tumour progression, studies identifying c-Myc regulators have gained momentum in the past few years. This increase in studies has led to the identification of miRNAs as novel regulators of c-Myc activity. For example, a study by Akao et al. ${ }^{77}$ demonstrated the regulation of c-Myc levels by miR-let-7a in human colon cancer cells. In xenograft models, let-7a stably-transfected cells reduced c-Myc levels and inhibited tumour growth in mice, thus confirming the tumour suppressor activity of let-7a. ${ }^{78}$ miR-34c, another important tumour suppressor miRNA, regulates c-Myc levels by directly binding c-Myc mRNA in the $3^{\prime}$-UTR region. ${ }^{79}$ Although miR-34c levels are under the control of $\mathrm{p} 53$, over-expression studies in pancreatic cancer cells have indicated that miR-34c exerts tumour suppressor activity even in the absence of p53. ${ }^{80}$ Taken together, these reports support the view that miRNAs present a novel switch for c-Myc activity, which could be useful in generating new therapeutic modalities against tumour growth.

Regulation of RAS-RAS mutations are a common driving force for tumorigenesis in cancers of multiple origins. For example, KRAS mutations are present in $>90 \%$ of pancreatic adenocarcinoma. ${ }^{81,82}$ Constitutive activation of Ras targets multiple signalling networks, such as Raf/MEK/ERK and PI3K/Akt, to transduce the oncogenic signals and commit the cells to RAS-mediated transformation. ${ }^{83}$ Apart from transformation, Kras also regulates cancer metabolism. ${ }^{84,85}$ Increasing evidence demonstrates a direct relationship between Kras, mitochondrial dysfunction and ROS production in tumour cells. Kras disrupts mitochondrial function by opening mitochondrial permeability pores, thus inactivating oxidative phosphorylation. ${ }^{86}$ Hence, in comparison to normal counterparts, Kras transformed cancer cells exhibit increased glycolysis. Also, Kras promotes tumour growth by decreasing pyruvate flux through the tricarboxylic acid (TCA) cycle and promoting glutamine metabolism. ${ }^{87}$

Owing to the universal role of Kras in tumorigenesis, various studies have investigated a possible link between Kras and miRNAs. Johnson et al. ${ }^{88}$ were the first to demonstrate a link and showed that Kras is a direct target of Let-7 miRNA in lung tumours. A similar association was also observed in the context of pancreatic cancer, in which miR-96 was found to down-regulate Kras levels. ${ }^{89}$ An inverse correlation between miR-143 and Kras has also been highlighted in colorectal cancer cells and prostate cancer cells. ${ }^{90,}{ }^{91}$ Interestingly, in pancreatic cancer cells, miR-143 is under the control of Kras, thus suggesting a feedback control provided by miR-143 on Kras levels. ${ }^{92}$ In pancreatic adenocarcinoma, miR-217 slows tumour growth and colony formation by targeting Kras. ${ }^{94}$ miR-217, in combination with miR-196a, provides significant sensitivity to distinguish between healthy tissue, pancreatic ductal adenocarcinoma and chronic pancreatitis in samples from fine needle 
aspirates. ${ }^{95}$ In addition, reciprocal relations between and miR-216b and Kras exist in cells derived from K-Ras;Pdx1-Cre;INK4a/Arf spontaneous model of pancreatic cancer. ${ }^{96}$

Regulation of HIF1a-HIF1a is a central mediator of oxygen homeostasis in mammalian systems. Hypoxic conditions are common in pancreatic tumours and the resultant activation of HIF1a critically regulates tumour growth and survival by inducing glycolysis, aerobic respiration and angiogenesis related factors, thus paving the foundation for aerobic glycolysis in cancer cells, also known as the Warburg effect. HIF1a controls glycolysis by upregulating the expression of key glycolytic enzymes, including GLUT-1, GLUT-3, HKII, PFK-L, ALD-A, PGK1, ENO- $a$, and PKM2. ${ }^{97-99}$ HIF1a also favours anaerobic respiration by activating PDK1 and LDHA in malignant cells. ${ }^{97-99}$

HIF1a is under the transcriptional control of mTOR as well as various oncogenes and growth factors, such as HRas, c-Myc, Src, EGF and HGF. ${ }^{100,101}$ miRNAs have also emerged as a new class of regulators that regulate HIF1a levels in tumours. HIF1a is a direct target of the miR-17-92 cluster, which itself is under the control of c-Myc. ${ }^{102}$ Such feedback regulation illustrates the complex interplay between c-Myc and HIF1a in tumours. Similarly, HIF1a is also regulated by other miRNAs. miR-199a mediates inhibition of HIF1a, potentially in a feedback manner through Twist-1. ${ }^{103,104}$ miR-20b also abrogates HIF1a levels under hypoxic conditions. ${ }^{105}$ Through HIF1a, miR-20b also regulates VEGF and angiogenesis in tumours. In addition, miR-519c, miR-107 and miR-155 also target HIF1a levels in endothelial cells, colon cancer cells and colorectal adenocarcinoma, respectively. ${ }^{106-108}$ These findings could have relevance for pancreatic cancer as miR-155 and miR-107 are part of the miRNA signature of pancreatic cancer ${ }^{26}$ Furthermore, miR155 is overexpressed in pancreatic intraepithelial neoplasia (PanIN)-2 and PanIN-3, in contrast to non-neoplastic ductal epithelium, suggesting it has a role in early pancreatic cancer pathogenesis. ${ }^{109,110}$ miR-155 levels are also increased in cyst fluid samples obtained from patients with noninvasive intraductal papillary mucinous neoplasm (IPMN), compared with those with benign pancreatic cysts. ${ }^{111}$ Overexpression studies suggest a positive correlation between HIF1a and miR-21 levels. miR-21 is overexpressed in PanIN-3 lesions, but not PanIN-2 lesions and hence might have a role to play in later stages of pancreatic cancer pathogenesis. ${ }^{109}$ Similarly, a role of hypoxia-induced miR-424 in stabilizing HIF1a has been reported. ${ }^{112}$ Under normoxic conditions, basal levels of HIF1a are maintained by the ubiquitin ligase system. However, demand of HIF1a is high under hypoxia and the degradation process needs to be under control. miR-424, differentially expressed in almost all tumour types, actively participates in slowing the turnover rate of HIF1a by targeting cullin 2 scaffolding protein for ubiquitin ligase system in human endothelial cells. Thus, miR-424 is crucial for HIF1a-derived tumorigenesis.

\section{Regulation of TCA machinery by miRNAs}

Cancer cells, like other rapidly proliferating cells, bypass oxidative phosphorylation (the TCA cycle) and rely mostly on non-oxidative pathways (lactate production) to meet their high energy demands. ${ }^{113}$ Moreover, this metabolic shift enables cancer cells to produce various building blocks, such as fatty acids, lipids, nucleotides and proteins, while still supplying sufficient energy. Interestingly, however, oxidative phosphorylation is not 
completely abolished in cancer cells and still operates at a low level. ${ }^{114}$ The preference of cancerous tissue for non-oxidative pathways is regulated through molecular switches such as c-Myc and HIF1a. Nevertheless, the role of miRNAs in coordinating these preferences cannot be underestimated. Accumulating evidence indicates that miRNAs directly and indirectly regulate the TCA cycle. The first evidence for direct regulation came from Wilfred et al., ${ }^{115}$ who predicted the role of miR-103 and miR-107 in regulating acetyl CoA and lipid levels in cellular systems. miR-210, another key regulator of mitochondrial function, directly represses SDHD (subunit D of succinate dehydrogenase complex), which is an important member of the TCA cycle and electron transport system in lung adenocarcinoma. ${ }^{28}$ Furthermore, miR-210, under the transcriptional control of HIF1a, negatively regulates the mitochondrial TCA cycle by targeting ISCU (iron-sulfur cluster scaffold homolog) and COX10 (Cytochrome c oxidase assembly protein) and hence switches the fate of pyruvate toward lactic acid conversion in breast and colon cancer cells. ${ }^{116}$ Given the increased levels of miR-210 in pancreatic cancer, it is expected that similar mechanisms might be operational in pancreatic cancer. ${ }^{28}$

With regard to indirect regulation of the TCA cycle, c-Myc mediates repression of mir-23a/23b to promote oxidative phosphorylation. ${ }^{117} \mathrm{c}-\mathrm{Myc}$ also replenishes glutamine, a TCA cycle substrate, through increased transcription of mitochondrial glutaminase and hence stabilizes mitochondrial metabolism and growth. ${ }^{17,118}$ This mechanism was confirmed by silencing glutaminase in c-Myc transfected cells, which led to reduced cell proliferation. ${ }^{117}$ Reciprocally, miRNAs can modulate the flux of glucose through TCA cycle by regulating c-Myc as described above. Besides c-Myc, p53 also modulates aerobic respiration in cancer cells through the synthesis of cytochrome c oxidase 2 (SCO2); inactivation of this gene induces aerobic respiratory failure. ${ }^{119}$ Interestingly, many miRNAs, including miR-125b, miR-30 and miR-504, target p53. ${ }^{73,120,121}$ Hence, these findings immediately suggest the possible control of oxidative phosphorylation through miRNAmediated p53 reduction in various tumours, including pancreatic cancer, in which differential expression of miR-125b has been reported. ${ }^{122}$

\section{Directing flux via glycolysis vs. TCA cycle}

Post glycolysis, pyruvate can undergo either aerobic or anaerobic respiration, depending on levels of lactacte dedehyrogenase A (LDHA), monocarboxylate transporters (MCTs) and pyruvate dehydrogenase (PDH). Oncogenes such as NF-kB, c-Myc and Akt directly or indirectly regulate these enzymes and preferentially drive anaerobic respiration in cancer cells. For example, HIF1a, upon oncogenic stimulation, upregulates $L D H A$ transcription with a concomitant increase in the PDH inactivating enzyme, pyruvate dehydrogenase kinase 1 (PDK1), and thus allows pyruvate to bypass aerobic respiration. 97-99,123,124 Similarly, c-Myc enhances lactate production through LDHA and PDK1 activation. ${ }^{125}$ These observations imply that any factor promoting HIF1a and c-Myc will indirectly favour lactic acid generation.

As miRNAs are critical regulators of HIF1a and c-Myc expression, they have a role in regulating the flux of glucose through either aerobic or anaerobic respiration. miR-103/107, which are critical for pancreatic tumerogenesis, ${ }^{126}$ have been shown to regulate PDK4, a 
critical inactivator of pyruvate dehydrogenase enzymatic activity. ${ }^{115}$ The $3^{\prime}$-UTR of PDK4 transcript is predicted to carry a miR-103/107 recognition sequence(s). ${ }^{115}$ LDHA is a direct target of miR-503-3p. ${ }^{127,128}$ The role of miR-375 in targeting lactate dehydrogenase B (LDHB) has also been highlighted. ${ }^{129}$ LDHB, which has the opposite function to LDHA (in that it converts lactate into pyruvate), may help glucose-deprived tumor or stromal cells utilize the lactate secreted by other tumor cells. In addition, a report by Zha et al. ${ }^{128}$ suggests that LDHB is a crucial factor in mTOR-mediated tumorigenesis. These findings might be important in the context of pancreatic neuroendocrine tumours as miR-375 is highly expressed in pancreatic $\beta$-cells. The secretion of lactate outside the cell is directly regulated by miR-29a, miR-29b and miR-124, which target the $3^{\prime}$-UTR of MCT1 in pancreatic $\beta$-cells. ${ }^{130}$

\section{Regulation of glutamine metabolism}

Research suggests that glutamine is another indispensable molecule for tumour growth and expansion. Although many amino acids might serve as a nitrogen source, tumour cells preferentially consume glutamine at a faster rate than any other amino acid. ${ }^{131}$ High levels of glutaminase and organic phosphorus, a cofactor for glutaminase activity, are linked with tumour cell proliferation. ${ }^{132}$ Glutaminase-mediated deamination results in the conversion of glutamine to glutamate, which further undergoes enzymatic conversion to form aketoglutarate, an important substrate for the TCA cycle. ${ }^{133}$ Thus, the apparent metabolic function for glutamine uptake is to sustain the TCA cycle in tumour cells, albeit at a low level. In addition to regulation by multiple factors in the tumour microenvironment, including oxygen deprivation, glutaminolysis is also regulated by miRNAs. Glutaminase enzyme is a direct target of miR-23a/b, and c-Myc-mediated reduction of these miRNAs rescues the enzyme and promotes glutaminolysis. ${ }^{117}$ As with most tumours, a crucial role of c-Myc in pancreatic tumorigenesis is well established. However, the exact role of miR-23a/b in pancreatic cancer remains to be explored. p53, a direct target of miR-125b, miR-30 and miR-504, also has a crucial role in maintaining glutamine levels through the activation of glutaminase 2 (GLS2), another important glutamine metabolizing enzyme. ${ }^{73,120,121} \mathrm{In}$ addition to glutamine breakdown, direct effects of miRNAs on glutamine synthesis are also evident. miR-29a, whose overexpression diminishes proliferation and invasiveness in pancreatic cancer cell lines, regulates glutamine levels in intestinal bowel disease by directly targeting glutamine synthetase and thus causing increased intestinal permeability in this disease. ${ }^{134-136}$ Similar mechanisms might also exist in pancreatic cancer, where miR-129 overexpression might provide glutamine as an alternative energy source.

\section{Regulation of fatty acid metabolism}

Altered lipid metabolism, although less well-recognized, is also an important factor in many tumours. In tumours, the PI3K/Akt pathway is centrally involved in fatty acid biogenesis through the activation of ATP citrate lyase and inhibition of fatty acid $\beta$-oxidation enzyme CPT1A. ${ }^{137,138}$ Given the important role of PI3K/Akt in the regulation of lipid metabolism in tumours, it is likely that miRNAs regulate lipid metabolism in tumours via this pathway. miR-21, which inhibits the PI3K/Akt pathway negative regulator PTEN, is induced in gemcitabine-resistant pancreatic cancer cells and is downregulated by curcumin or its analogue CDF. ${ }^{139}$ Although not much is known about miRNA-mediated direct regulation of 
fatty acid metabolism in pancreatic cancer, fatty acid metabolism is crucial for pancreatic cancer initiation and progression. A high-fat-diet that triggers inflammation in Kras animal models of pancreatic cancer aggravates tumour promotion. ${ }^{140}$ This tumour promotion is caused by dramatic changes in energy metabolism through enhancement of pancreatic exocrine insufficiency, metabolic rates, and expression of genes involved in mitochondrial fatty acid $\beta$-oxidation. ${ }^{140}$ Obesity and a high fat diet are directly linked with the incidence of human pancreatic cancer. ${ }^{141-143}$

\section{The tumour microenvironment and miRNAs}

The tumour microenvironment (often termed the stroma) is central to tumour growth and progression. The importance of the environment can be understood by the fact that most cells surrounding a tumour show abnormal behaviour and genetic instability. Cancer cells grown in the vicinity of fibroblasts have increased mitochondrial mass; on the other hand, the fibroblasts in such co-cultures demonstrate a dramatic loss of mitochondria. ${ }^{144}$ This observation indicates the parasitic role of tumours in drawing essential nutrients from the surrounding environment. Given the critical role of the stroma in maintaining the aggressive behaviour of a tumour, a multitude of studies are focusing on controlling tumour growth through stromal alteration. In this regard, miRNAs associated with stromal components might prove to be a valuable therapeutic target.

To date, a number of miRNAs have been evaluated for their effects on stromal cellular and non-cellular components. For cancer-associated fibroblasts, various studies have reported an upregulation of miR-16, miR-320, miR-504, miR-424 (a cluster of miRNAs found on chromosomal location Xq26.3.), miR-29b and miR-146a. ${ }^{145,146}$ Although the roles of miR-16 and miR-320 are still not clear, the other miRNAs were shown to regulate cancerassociated fibroblast genes. Of note, miR-504 and miR-424 also have a crucial role in cancer metabolism through the activation of HIF1a and suppression of p53 in tumour cells. ${ }^{112,147}$ Levels of miR-31, which is associated with oxidative stress and activation of the hypoxic response, are also reduced in cancer-associated fibroblasts. ${ }^{148}$ A key miRNA that is readily detectable in the plasma of patients with pancreatic cancer is miR-10b. ${ }^{149}$ Expression of this miRNA is increased in cancer cells compared with CK19-positive epithelial cells in benign lesions from endoscopic ultrasonography-guided fine-needle aspirate (EUS-FNA) samples. ${ }^{149}$ Although miR-10b does not directly target metabolic genes, it regulates the expression of HoxD10, which in turn can regulate angiogenesis and expression of MMP14 and UPAR, which cause remodelling of the pancreatic tumor microenvironment. ${ }^{150,151}$ Thus, it seems that by modulating the tumour microenvironment, miR-10b can alter the tumourstromal metabolic interactions in pancreatic adenocarcinoma.

\section{Can miRNAs differentiate pancreatic disease?}

Given the crucial role of miRNAs in coordinating vast metabolic processes, many studies have investigated the possible links between miRNA expression and cancer progression. With regard to pancreatic cancer, an avalanche of microarray data has produced a long list of differentially expressed miRNAs. Bloomston et al. ${ }^{27}$ compared the miRNA profile of pancreatic cancer, chronic pancreatitis (an inflammatory state of the pancreas, which is 
associated with the increased risk of pancreatic cancer ${ }^{152}$ ) and normal pancreas. According to their findings, a total of 30 miRNAs were upregulated and 3 miRNAs were downregulated in pancreatic cancer compared with normal pancreas; chronic pancreatitis demonstrated an overexpression of 22 miRNAs and suppression of 2 miRNAs compared with normal pancreas. In comparison with chronic pancreatitis, 15 miRNAs were upregulated and 8 miRNAs were downregulated in pancreatic cancer. Corroborating these studies, Lee et $a l .{ }^{26}$ also investigated the miRNA expression profile of pancreatic cancer by assessing 200 miRNAs in clinical samples of pancreatic cancer. Similarly, Ali et al. ${ }^{153}$ identified differentially expressed miRNAs in the plasma of patients with pancreatic cancer versus healthy volunteers. miRNA status has also been extensively investigated in 21 human pancreatic adenocarcinoma cell lines compared with normal counterparts. ${ }^{23}$

Importantly, these studies identified a group of miRNAs that seem to underlie or drive the pathophysiology of chronic pancreatitis and/or pancreatic cancer. Moreover, the comparison between chronic pancreatitis and pancreatic cancer pinned down the key miRNAs associated with the altered metabolic states of the respective diseases. For example, in the study by Bloomston et al.,${ }^{27}$ of the 30 overexpressed miRNAs in pancreatic cancer, 12 miRNAs are hypoxamir (miRNA associated with hypoxia), which is in line with the low oxygen environment of pancreatic tumours; in chronic pancreatitis, which is more of an inflammatory state, only 2 of the 22 miRNAs are hypoxia responsive. Similarly, in contrast to chronic pancreatitis, pancreatic tumours demonstrate an increased expression of glucose responsive miRNAs, such as miR-221 and miR-21. Chronic pancreatitis causes altered expression of a number of ROS-associated miRNAs compared with pancreatic tumour samples; 4 out of 22 miRNAs in chronic pancreatitis are ROS responsive (according to other studies; miR-339, miR-128b, miR-125b-1/2). ${ }^{154,155}$ However, in pancreatic tumours only miR-125a is ROS-responsive.

\section{Metabolic miRNAs in plasma as biomarkers}

Given that miRNAs are markers of the metabolic state, they can be used as a potent tool to monitor cancer progression and the effectiveness of cancer therapeutics. Sensitivity to chemo-therapy is governed by the metabolic state of the tumour. 18-FDG-PET imaging, which measures glucose uptake and metabolism in tumours, is being successfully used for cancer staging and for assessing tumour response to therapy in pancreatic cancer. ${ }^{156}$ Furthermore, direct inhibitors of glycolysis have demonstrated marked inhibition of growth in pancreatic cancer cells under cell culture conditions. ${ }^{157}$ miR-214, which is downregulated in pancreatic cancer and determines sensitivity of pancreatic cancer cells to gemcitabine, targets PTEN in ovarian cancer and might induce mTOR-mediated activation of aerobic glycolysis in pancreatic cancer. ${ }^{56,158}$ miR-210, a HIF1a-inducible miRNA is upregulated in the plasma of patients with pancreatic cancer. ${ }^{159,160}$ This miRNA targets enzyme glycerol-3-phosphate dehydrogenase 1-like (GAPD1L), inhibits PHD activity and stabilizes HIF1a in a positive feedback fashion. ${ }^{161}$ Plasma levels of miR-21, which downregulates PTEN, are increased in patients with pancreatic cancer compared with healthy controls. ${ }^{153}$ Expression of miR-21 is high in chemoresistant cell line models of pancreatic cancer and is correlated with worse prognosis in pancreatic cancer. ${ }^{153}$ In contrast to levels of miR-21, levels of miR-320 family members, which downregulate insulin-like growth factor 1 
(IGF-1), are substantially reduced in plasma from patients with pancreatic cancer compared with healthy controls. ${ }^{153}$ The upregulation of miR-21 and downregulation of miR-320s indicates the RTK-mediated activation of mTOR signalling. Another miRNA that is overexpressed in the plasma of patients with pancreatic cancer and serves as a potential biomarker for disease prognosis and a biomarker for early pancreatic neoplasia, is miR-155. ${ }^{109,111,149,162,163}$ miR-155 levels might determine gemcitabine sensitivity in patients with pancreatic cancer by regulating the levels of cytidine deaminase. ${ }^{164,165}$

\section{Conclusions}

Cancer metabolism and the role of miRNAs are rapidly growing research fields, which could soon unfold the secrets to check cancer-associated mortality. Here, we have summarized findings pertaining to metabolic reprogramming by miRNAs in pancreatic cancer. Current knowledge suggests that in response to various oncogenic or microenvironment signals, miRNAs regulate cellular metabolism to facilitate tumour growth, metastasis and survival of tumour cells under harsh conditions. Although this Review has provided a thorough insight into miRNA responsive and inducible factors, and the regulated molecular pathways, further studies are warranted regarding their biogenesis in the context of metabolic states of the tumour cells. It is essential to understand the key metabolic switches favouring the expression of a particular set of miRNAs. Similarly, an understanding of potential inactivating mutations in the 3'-UTR of the miRNA target mRNAs will be of clinical significance. Furthermore, how the miRNA machinery regulates the overall metabolic state of the tumour, including the stroma, so as to facilitate progression of this lethal disease, remains to be answered.

\section{Review criteria}

Relevant literature on the metabolic alterations, contributing miRNAs and clinical outcome in pancreatic cancer were systematically identified by searching the PubMed database for articles published up to Jan 2012. The search terms used in combination with "pancreatic cancer" were: "miRNA", "metabolism", "IPMN", "PanIN", "p53”, “mTOR”, "HIF1”, "myc" and "ras". All papers identified were English-language, full-text original research articles published in peer-reviewed journals.

\section{Acknowledgments}

This work was supported by SPORE (P50 CA127297, NCI) Career Development Award to P.K.S., SPORE (P50 CA127297, NCI) Developmental Research Project Award to P.K.S., and Cancer Prevention and Control Nutrition seed grant $(15618, \mathrm{GSCN})$ to P.K.S. The funders had no role in preparation of the manuscript.

\section{About the Authors}

Dr. Pankaj K. Singh is an Assistant professor at the Eppley Institute for Research in Cancer and Allied Diseases, University of Nebraska medical Center, Omaha, NE. He is a courtesy faculty at the departments of Biochemistry and Molecular Biology, and Genetics, Cell Biology and Anatomy, University of Nebraska Medical Center. He is a SPORE Career Development Awardee since 2010. His current research interests include metabolism alterations in pancreatic cancer. 
Dr. Randall E. Brand is Professor of Medicine at the University of Pittsburgh School of Medicine, Pittsburgh, PA. He is the Academic Director of the GI Division at Shadyside Hospital and Director of the GI Malignancy Early Detection, Diagnosis \& Prevention Program. He has an interest in early detection and screening for pancreatic cancer.

Dr. Kamiya Mehla is a post-doctoral researcher at the University of Nebraska Medical Center, Omaha, NE. She finished her doctoral degree from the Institute of Genomics and Integrative Biology (University of Pune), New Delhi, India in 2011. She has research interest in cancer metabolism and immunological aspects of type I diabetes.

\section{References}

1. Jemal A, Siegel R, Xu J, Ward E. Cancer statistics, 2010. CA Cancer J Clin. 2010; 60:277-300. [PubMed: 20610543]

2. Pizzi S, et al. Glucose transporter-1 expression and prognostic significance in pancreatic carcinogenesis. Histol Histopathol. 2009; 24:175-85. [PubMed: 19085834]

3. Dong X, Tang H, Hess KR, Abbruzzese JL, Li D. Glucose metabolism gene polymorphisms and clinical outcome in pancreatic cancer. Cancer. 2011; 117:480-91. [PubMed: 20845477]

4. Jiao Y, et al. DAXX/ATRX, MEN1, and mTOR pathway genes are frequently altered in pancreatic neuroendocrine tumors. Science. 2011; 331:1199-203. [PubMed: 21252315]

5. Jones $\mathrm{S}$, et al. Core signaling pathways in human pancreatic cancers revealed by global genomic analyses. Science. 2008; 321:1801-6. [PubMed: 18772397]

6. Wang X, et al. Polymorphisms in the hypoxia-inducible factor-1alpha gene confer susceptibility to pancreatic cancer. Cancer Biol Ther. 2011; 12:383-7. [PubMed: 21709439]

7. Lee SM, et al. Improved prognostic value of standardized uptake value corrected for blood glucose level in pancreatic cancer using F-18 FDG PET. Clin Nucl Med. 2011; 36:331-6. [PubMed: 21467846]

8. van Heertum RL, Fawwaz RA. The role of nuclear medicine in the evaluation of pancreatic disease. Surg Clin North Am. 2001; 81:345-58. [PubMed: 11392421]

9. Krol J, Loedige I, Filipowicz W. The widespread regulation of microRNA biogenesis, function and decay. Nat Rev Genet. 2010; 11:597-610. [PubMed: 20661255]

10. Fabbri M, Croce CM, Calin GA. MicroRNAs. Cancer J. 2008; 14:1-6. [PubMed: 18303474]

11. Slaby O, Bienertova-Vasku J, Svoboda M, Vyzula R. Genetic polymorphisms and MicroRNAs: new direction in molecular epidemiology of solid cancer. J Cell Mol Med. 2011

12. Iorio MV, Croce CM. MicroRNAs in cancer: small molecules with a huge impact. J Clin Oncol. 2009; 27:5848-56. [PubMed: 19884536]

13. Croce CM. Causes and consequences of microRNA dysregulation in cancer. Nat Rev Genet. 2009; 10:704-14. [PubMed: 19763153]

14. Simone NL, et al. Ionizing radiation-induced oxidative stress alters miRNA expression. PLoS One. 2009; 4:e6377. [PubMed: 19633716]

15. Wang Z, et al. Profiles of oxidative stress-related microRNA and mRNA expression in auditory cells. Brain Res. 2010; 1346:14-25. [PubMed: 20510889]

16. Kulshreshtha R, Davuluri RV, Calin GA, Ivan M. A microRNA component of the hypoxic response. Cell Death Differ. 2008; 15:667-71. [PubMed: 18219318]

17. Kulshreshtha R, et al. Regulation of microRNA expression: the hypoxic component. Cell Cycle. 2007; 6:1426-31. [PubMed: 17582223]

18. Ishikawa K, et al. ROS-generating mitochondrial DNA mutations can regulate tumor cell metastasis. Science. 2008; 320:661-4. [PubMed: 18388260]

19. Weinberg F, et al. Mitochondrial metabolism and ROS generation are essential for Kras-mediated tumorigenicity. Proc Natl Acad Sci U S A. 2010; 107:8788-93. [PubMed: 20421486] 
20. Galanis A, et al. Reactive oxygen species and HIF-1 signalling in cancer. Cancer Lett. 2008; 266:12-20. [PubMed: 18378391]

21. Xia C, et al. Reactive oxygen species regulate angiogenesis and tumor growth through vascular endothelial growth factor. Cancer Res. 2007; 67:10823-30. [PubMed: 18006827]

22. Wang Z, et al. Profiles of oxidative stress-related microRNA and mRNA expression in auditory cells. Brain Res. 2010; 1346:14-25. [PubMed: 20510889]

23. Kent OA, et al. A resource for analysis of microRNA expression and function in pancreatic ductal adenocarcinoma cells. Cancer Biol Ther. 2009; 8:2013-24. [PubMed: 20037478]

24. Ruan K, Song G, Ouyang G. Role of hypoxia in the hallmarks of human cancer. J Cell Biochem. 2009; 107:1053-62. [PubMed: 19479945]

25. Kulshreshtha R, et al. A microRNA signature of hypoxia. Mol Cell Biol. 2007; 27:1859-67. [PubMed: 17194750]

26. Lee EJ, et al. Expression profiling identifies microRNA signature in pancreatic cancer. Int J Cancer. 2007; 120:1046-54. [PubMed: 17149698]

27. Bloomston M, et al. MicroRNA expression patterns to differentiate pancreatic adenocarcinoma from normal pancreas and chronic pancreatitis. JAMA. 2007; 297:1901-8. [PubMed: 17473300]

28. Favaro E, et al. MicroRNA-210 regulates mitochondrial free radical response to hypoxia and krebs cycle in cancer cells by targeting iron sulfur cluster protein ISCU. PLoS One. 2010; 5:e10345. [PubMed: 20436681]

29. Greither T, et al. Elevated expression of microRNAs 155, 203, 210 and 222 in pancreatic tumors is associated with poorer survival. Int J Cancer. 2010; 126:73-80. [PubMed: 19551852]

30. Yan H, et al. MicroRNA-20a overexpression inhibited proliferation and metastasis of pancreatic carcinoma cells. Hum Gene Ther. 2010; 21:1723-34. [PubMed: 20583868]

31. Giovannucci E, Michaud D. The role of obesity and related metabolic disturbances in cancers of the colon, prostate, and pancreas. Gastroenterology. 2007; 132:2208-25. [PubMed: 17498513]

32. Esguerra JL, Bolmeson C, Cilio CM, Eliasson L. Differential glucose-regulation of microRNAs in pancreatic islets of non-obese type 2 diabetes model Goto-Kakizaki rat. PLoS One. 2011; 6:e18613. [PubMed: 21490936]

33. Tang X, Muniappan L, Tang G, Ozcan S. Identification of glucose-regulated miRNAs from pancreatic \{beta\} cells reveals a role for miR-30d in insulin transcription. RNA. 2009; 15:287-93. [PubMed: 19096044]

34. Thorens B, Mueckler M. Glucose transporters in the 21st Century. Am J Physiol Endocrinol Metab. 2011; 298:E141-5. [PubMed: 20009031]

35. Reske SN, et al. Overexpression of glucose transporter 1 and increased FDG uptake in pancreatic carcinoma. J Nucl Med. 1997; 38:1344-8. [PubMed: 9293784]

36. Ito H, Duxbury M, Zinner MJ, Ashley SW, Whang EE. Glucose transporter-1 gene expression is associated with pancreatic cancer invasiveness and MMP-2 activity. Surgery. 2004; 136:548-56. [PubMed: 15349101]

37. Ciaraldi TP, Abrams L, Nikoulina S, Mudaliar S, Henry RR. Glucose transport in cultured human skeletal muscle cells. Regulation by insulin and glucose in nondiabetic and non-insulin-dependent diabetes mellitus subjects. J Clin Invest. 1995; 96:2820-7. [PubMed: 8675652]

38. Rincon J, et al. Mechanisms behind insulin resistance in rat skeletal muscle after oophorectomy and additional testosterone treatment. Diabetes. 1996; 45:615-21. [PubMed: 8621012]

39. Sakoda H, et al. Dexamethasone-induced insulin resistance in 3T3-L1 adipocytes is due to inhibition of glucose transport rather than insulin signal transduction. Diabetes. 2000; 49:1700-8. [PubMed: 11016454]

40. Matosin-Matekalo M, Mesonero JE, Laroche TJ, Lacasa M, Brot-Laroche E. Glucose and thyroid hormone co-regulate the expression of the intestinal fructose transporter GLUT5. Biochem J. 1999; 339(Pt 2):233-9. [PubMed: 10191252]

41. Flier JS, Mueckler MM, Usher P, Lodish HF. Elevated levels of glucose transport and transporter messenger RNA are induced by ras or src oncogenes. Science. 1987; 235:1492-5. [PubMed: 3103217] 
42. Osthus RC, et al. Deregulation of glucose transporter 1 and glycolytic gene expression by c-Myc. J Biol Chem. 2000; 275:21797-800. [PubMed: 10823814]

43. Egert S, Nguyen N, Brosius FC 3rd, Schwaiger M. Effects of wortmannin on insulin- and ischemia-induced stimulation of GLUT4 translocation and FDG uptake in perfused rat hearts. Cardiovasc Res. 1997; 35:283-93. [PubMed: 9349391]

44. Yeh JI, Gulve EA, Rameh L, Birnbaum MJ. The effects of wortmannin on rat skeletal muscle. Dissociation of signaling pathways for insulin- and contraction-activated hexose transport. J Biol Chem. 1995; 270:2107-11. [PubMed: 7836438]

45. Behrooz A, Ismail-Beigi F. Dual control of glut1 glucose transporter gene expression by hypoxia and by inhibition of oxidative phosphorylation. J Biol Chem. 1997; 272:5555-62. [PubMed: 9038162]

46. Russell RR 3rd, Bergeron R, Shulman GI, Young LH. Translocation of myocardial GLUT-4 and increased glucose uptake through activation of AMPK by AICAR. Am J Physiol. 1999; 277:H643-9. [PubMed: 10444490]

47. Chow TF, et al. The miR-17-92 cluster is over expressed in and has an oncogenic effect on renal cell carcinoma. J Urol. 2010; 183:743-51. [PubMed: 20022054]

48. Karolina DS, et al. MicroRNA 144 Impairs Insulin Signaling by Inhibiting the Expression of Insulin Receptor Substrate 1 in Type 2 Diabetes Mellitus. PLoS One. 2011; 6:e22839. [PubMed: 21829658]

49. Szafranska AE, et al. MicroRNA expression alterations are linked to tumorigenesis and nonneoplastic processes in pancreatic ductal adenocarcinoma. Oncogene. 2007; 26:4442-52. [PubMed: 17237814]

50. Srivastava SK, et al. MicroRNA-150 directly targets MUC4 and suppresses growth and malignant behavior of pancreatic cancer cells. Carcinogenesis. 2011

51. Coulouarn C, Factor VM, Andersen JB, Durkin ME, Thorgeirsson SS. Loss of miR-122 expression in liver cancer correlates with suppression of the hepatic phenotype and gain of metastatic properties. Oncogene. 2009; 28:3526-36. [PubMed: 19617899]

52. Aqeilan RI, Calin GA, Croce CM. miR-15a and miR-16-1 in cancer: discovery, function and future perspectives. Cell Death Differ. 2010; 17:215-20. [PubMed: 19498445]

53. Calin GA, et al. MiR-15a and miR-16-1 cluster functions in human leukemia. Proc Natl Acad Sci U S A. 2008; 105:5166-71. [PubMed: 18362358]

54. Shea CM, Tzertzinis G. Controlled expression of functional miR-122 with a ligand inducible expression system. BMC Biotechnol. 2010; 10:76. [PubMed: 20961424]

55. Tsai WC, et al. MicroRNA-122, a tumor suppressor microRNA that regulates intrahepatic metastasis of hepatocellular carcinoma. Hepatology. 2009; 49:1571-82. [PubMed: 19296470]

56. Zhang XJ, et al. Dysregulation of miR-15a and miR-214 in human pancreatic cancer. J Hematol Oncol. 2010; 3:46. [PubMed: 21106054]

57. Nicholson RI, Gee JM, Harper ME. EGFR and cancer prognosis. Eur J Cancer. 2001; 37(Suppl 4):S9-15. [PubMed: 11597399]

58. Ebert M, et al. Induction of platelet-derived growth factor A and B chains and over-expression of their receptors in human pancreatic cancer. Int J Cancer. 1995; 62:529-35. [PubMed: 7665222]

59. Sharma SV, Bell DW, Settleman J, Haber DA. Epidermal growth factor receptor mutations in lung cancer. Nat Rev Cancer. 2007; 7:169-81. [PubMed: 17318210]

60. Yu J, Ustach C, Kim HR. Platelet-derived growth factor signaling and human cancer. J Biochem Mol Biol. 2003; 36:49-59. [PubMed: 12542975]

61. Sun Q, et al. Mammalian target of rapamycin up-regulation of pyruvate kinase isoenzyme type M2 is critical for aerobic glycolysis and tumor growth. Proc Natl Acad Sci U S A. 2011; 108:4129-34. [PubMed: 21325052]

62. Hitosugi T, et al. Tyrosine phosphorylation inhibits PKM2 to promote the Warburg effect and tumor growth. Sci Signal. 2009; 2:ra73. [PubMed: 19920251]

63. Li Y, et al. miR-146a suppresses invasion of pancreatic cancer cells. Cancer Res. 2010; 70:148695. [PubMed: 20124483] 
64. Hatakeyama H, et al. Regulation of heparin-binding EGF-like growth factor by miR-212 and acquired cetuximab-resistance in head and neck squamous cell carcinoma. PLoS One. 2010; 5:e12702. [PubMed: 20856931]

65. Molnar V, et al. MicroRNA-132 targets HB-EGF upon IgE-mediated activation in murine and human mast cells. Cell Mol Life Sci. 2011

66. Park JK, et al. miR-132 and miR-212 are increased in pancreatic cancer and target the retinoblastoma tumor suppressor. Biochem Biophys Res Commun. 2011; 406:518-23. [PubMed: 21329664]

67. Ito Y, et al. Expression of heparin-binding epidermal growth factor-like growth factor in pancreatic adenocarcinoma. Int J Pancreatol. 2001; 29:47-52. [PubMed: 11558632]

68. Vousden KH, Ryan KM. p53 and metabolism. Nat Rev Cancer. 2009; 9:691-700. [PubMed: 19759539]

69. Deberardinis RJ, Sayed N, Ditsworth D, Thompson CB. Brick by brick: metabolism and tumor cell growth. Curr Opin Genet Dev. 2008; 18:54-61. [PubMed: 18387799]

70. Matoba S, et al. p53 regulates mitochondrial respiration. Science. 2006; 312:1650-3. [PubMed: 16728594]

71. Okamura S, et al. Identification of seven genes regulated by wild-type p53 in a colon cancer cell line carrying a well-controlled wild-type p53 expression system. Oncol Res. 1999; 11:281-5. [PubMed: 10691030]

72. Ferecatu I, et al. Mitochondrial localization of the low level p53 protein in proliferative cells. Biochem Biophys Res Commun. 2009; 387:772-7. [PubMed: 19635458]

73. Le MT, et al. MicroRNA-125b is a novel negative regulator of p53. Genes Dev. 2009; 23:862-76. [PubMed: 19293287]

74. Zhang Y, et al. MicroRNA 125a and its regulation of the p53 tumor suppressor gene. FEBS Lett. 2009; 583:3725-30. [PubMed: 19818772]

75. Dang CV, Le A, Gao P. MYC-induced cancer cell energy metabolism and therapeutic opportunities. Clin Cancer Res. 2009; 15:6479-83. [PubMed: 19861459]

76. Gordan JD, Thompson CB, Simon MC. HIF and c-Myc: sibling rivals for control of cancer cell metabolism and proliferation. Cancer Cell. 2007; 12:108-13. [PubMed: 17692803]

77. Akao Y, Nakagawa Y, Naoe T. let-7 microRNA functions as a potential growth suppressor in human colon cancer cells. Biol Pharm Bull. 2006; 29:903-6. [PubMed: 16651716]

78. He XY, et al. The let-7a microRNA protects from growth of lung carcinoma by suppression of kRas and c-Myc in nude mice. J Cancer Res Clin Oncol. 2010; 136:1023-8. [PubMed: 20033209]

79. Cannell IG, Bushell M. Regulation of Myc by miR-34c: A mechanism to prevent genomic instability? Cell Cycle. 2010; 9:2726-30. [PubMed: 20603603]

80. Ji Q, et al. MicroRNA miR-34 inhibits human pancreatic cancer tumor-initiating cells. PLoS One. 2009; 4:e6816. [PubMed: 19714243]

81. Motojima K, et al. Mutations in the Kirsten-ras oncogene are common but lack correlation with prognosis and tumor stage in human pancreatic carcinoma. Am J Gastroenterol. 1991; 86:1784-8. [PubMed: 1962623]

82. Howe JR, Conlon KC. The molecular genetics of pancreatic cancer. Surg Oncol. 1997; 6:1-18. [PubMed: 9364657]

83. Downward J. Targeting RAS signalling pathways in cancer therapy. Nat Rev Cancer. 2003; 3:1122. [PubMed: 12509763]

84. Vizan P, et al. K-ras codon-specific mutations produce distinctive metabolic phenotypes in NIH3T3 mice [corrected] fibroblasts. Cancer Res. 2005; 65:5512-5. [PubMed: 15994921]

85. Chiaradonna F, Gaglio D, Vanoni M, Alberghina L. Expression of transforming K-Ras oncogene affects mitochondrial function and morphology in mouse fibroblasts. Biochim Biophys Acta. 2006; 1757:1338-56. [PubMed: 16987493]

86. $\mathrm{Hu} \mathrm{Y}$, et al. K-ras $(\mathrm{G} 12 \mathrm{~V})$ transformation leads to mitochondrial dysfunction and a metabolic switch from oxidative phosphorylation to glycolysis. Cell Res. 2011

87. Gaglio D, et al. Oncogenic K-Ras decouples glucose and glutamine metabolism to support cancer cell growth. Mol Syst Biol. 2011; 7:523. [PubMed: 21847114] 
88. Johnson SM, et al. RAS is regulated by the let-7 microRNA family. Cell. 2005; 120:635-47. [PubMed: 15766527]

89. Yu S, et al. miRNA-96 suppresses KRAS and functions as a tumor suppressor gene in pancreatic cancer. Cancer Res. 2010; 70:6015-25. [PubMed: 20610624]

90. Chen X, et al. Role of miR-143 targeting KRAS in colorectal tumorigenesis. Oncogene. 2009; 28:1385-92. [PubMed: 19137007]

91. Xu B, et al. miR-143 decreases prostate cancer cells proliferation and migration and enhances their sensitivity to docetaxel through suppression of KRAS. Mol Cell Biochem. 2011; 350:207-13. [PubMed: 21197560]

92. Kent OA, et al. Repression of the miR-143/145 cluster by oncogenic Ras initiates a tumorpromoting feed-forward pathway. Genes Dev. 2010; 24:2754-9. [PubMed: 21159816]

93. Shin KH, et al. miR-181a shows tumor suppressive effect against oral squamous cell carcinoma cells by downregulating K-ras. Biochem Biophys Res Commun. 2011; 404:896-902. [PubMed: 21167132]

94. Zhao WG, et al. The miR-217 microRNA functions as a potential tumor suppressor in pancreatic ductal adenocarcinoma by targeting KRAS. Carcinogenesis. 2010; 31:1726-33. [PubMed: 20675343]

95. Szafranska AE, et al. Analysis of microRNAs in pancreatic fine-needle aspirates can classify benign and malignant tissues. Clin Chem. 2008; 54:1716-24. [PubMed: 18719196]

96. Ali S, et al. Inactivation of Ink4a/Arf leads to deregulated expression of miRNAs in K-Ras transgenic mouse model of pancreatic cancer. J Cell Physiol. 2011

97. Semenza GL. Defining the role of hypoxia-inducible factor 1 in cancer biology and therapeutics. Oncogene. 2010; 29:625-34. [PubMed: 19946328]

98. Semenza GL. HIF-1: upstream and downstream of cancer metabolism. Curr Opin Genet Dev. 2010; 20:51-6. [PubMed: 19942427]

99. Kroemer G, Pouyssegur J. Tumor cell metabolism: cancer's Achilles' heel. Cancer Cell. 2008; 13:472-82. [PubMed: 18538731]

100. Hudson CC, et al. Regulation of hypoxia-inducible factor 1alpha expression and function by the mammalian target of rapamycin. Mol Cell Biol. 2002; 22:7004-14. [PubMed: 12242281]

101. Tacchini L, Dansi P, Matteucci E, Desiderio MA. Hepatocyte growth factor signalling stimulates hypoxia inducible factor-1 (HIF-1) activity in HepG2 hepatoma cells. Carcinogenesis. 2001; 22:1363-71. [PubMed: 11532856]

102. Taguchi A, et al. Identification of hypoxia-inducible factor-1 alpha as a novel target for miR-17-92 microRNA cluster. Cancer Res. 2008; 68:5540-5. [PubMed: 18632605]

103. Rane S, et al. Downregulation of miR-199a derepresses hypoxia-inducible factor-1alpha and Sirtuin 1 and recapitulates hypoxia preconditioning in cardiac myocytes. Circ Res. 2009; 104:879-86. [PubMed: 19265035]

104. Lee YB, et al. Twist-1 regulates the miR-199a/214 cluster during development. Nucleic Acids Res. 2009; 37:123-8. [PubMed: 19029138]

105. Lei Z, et al. Regulation of HIF-1alpha and VEGF by miR-20b tunes tumor cells to adapt to the alteration of oxygen concentration. PLoS One. 2009; 4:e7629. [PubMed: 19893619]

106. Cha ST, et al. MicroRNA-519c suppresses hypoxia-inducible factor-1alpha expression and tumor angiogenesis. Cancer Res. 2010; 70:2675-85. [PubMed: 20233879]

107. Yamakuchi M, et al. P53-induced microRNA-107 inhibits HIF-1 and tumor angiogenesis. Proc Natl Acad Sci U S A. 2010; 107:6334-9. [PubMed: 20308559]

108. Bruning U, et al. MicroRNA-155 Promotes Resolution of Hypoxia-Inducible Factor 1 \{alpha\} Activity during Prolonged Hypoxia. Mol Cell Biol. 2011; 31:4087-96. [PubMed: 21807897]

109. Ryu JK, et al. Aberrant MicroRNA-155 expression is an early event in the multistep progression of pancreatic adenocarcinoma. Pancreatology. 2010; 10:66-73. [PubMed: 20332664]

110. Yu J, Li A, Hong SM, Hruban RH, Goggins M. MicroRNA Alterations of Pancreatic Intraepithelial Neoplasms (PanINs). Clin Cancer Res. 2011

111. Habbe N, et al. MicroRNA miR-155 is a biomarker of early pancreatic neoplasia. Cancer Biol Ther. 2009; 8:340-6. [PubMed: 19106647] 
112. Ghosh G, et al. Hypoxia-induced microRNA-424 expression in human endothelial cells regulates HIF-alpha isoforms and promotes angiogenesis. J Clin Invest. 2010; 120:4141-54. [PubMed: 20972335]

113. Vander Heiden MG, Cantley LC, Thompson CB. Understanding the Warburg effect: the metabolic requirements of cell proliferation. Science. 2009; 324:1029-33. [PubMed: 19460998]

114. Dajani RM, Danielski J, Gamble W, Orten JM. Astudy of the citric acid cycle in certain tumour tissue. Biochem J. 1961; 81:494-503. [PubMed: 13883157]

115. Wilfred BR, Wang WX, Nelson PT. Energizing miRNA research: a review of the role of miRNAs in lipid metabolism, with a prediction that miR-103/107 regulates human metabolic pathways. Mol Genet Metab. 2007; 91:209-17. [PubMed: 17521938]

116. Puissegur MP, et al. miR-210 is overexpressed in late stages of lung cancer and mediates mitochondrial alterations associated with modulation of HIF-1 activity. Cell Death Differ. 2011; 18:465-78. [PubMed: 20885442]

117. Gao P, et al. c-Myc suppression of miR-23a/b enhances mitochondrial glutaminase expression and glutamine metabolism. Nature. 2009; 458:762-5. [PubMed: 19219026]

118. Wise DR, et al. Myc regulates a transcriptional program that stimulates mitochondrial glutaminolysis and leads to glutamine addiction. Proc Natl Acad Sci U S A. 2008; 105:18782-7. [PubMed: 19033189]

119. Baden KN, Murray J, Capaldi RA, Guillemin K. Early developmental pathology due to cytochrome c oxidase deficiency is revealed by a new zebrafish model. J Biol Chem. 2007; 282:34839-49. [PubMed: 17761683]

120. Li J, et al. miR-30 regulates mitochondrial fission through targeting p53 and the dynamin-related protein-1 pathway. PLoS Genet. 2010; 6:e1000795. [PubMed: 20062521]

121. Hu W, et al. Glutaminase 2, a novel p53 target gene regulating energy metabolism and antioxidant function. Proc Natl Acad Sci U S A. 2010; 107:7455-60. [PubMed: 20378837]

122. Jung DE, Wen J, Oh T, Song SY. Differentially Expressed MicroRNAs in Pancreatic Cancer Stem Cells. Pancreas. 2011; 40:1180-7. [PubMed: 21785383]

123. Papandreou I, Cairns RA, Fontana L, Lim AL, Denko NC. HIF-1 mediates adaptation to hypoxia by actively downregulating mitochondrial oxygen consumption. Cell Metab. 2006; 3:187-97. [PubMed: 16517406]

124. Semenza GL, et al. Hypoxia response elements in the aldolase A, enolase 1, and lactate dehydrogenase A gene promoters contain essential binding sites for hypoxia inducible factor 1 . $\mathbf{J}$ Biol Chem. 1996; 271:32529-37. [PubMed: 8955077]

125. Kim JW, Gao P, Liu YC, Semenza GL, Dang CV. Hypoxia-inducible factor 1 and dysregulated cMyc cooperatively induce vascular endothelial growth factor and metabolic switches hexokinase 2 and pyruvate dehydrogenase kinase 1. Mol Cell Biol. 2007; 27:7381-93. [PubMed: 17785433]

126. Roldo C, et al. MicroRNA expression abnormalities in pancreatic endocrine and acinar tumors are associated with distinctive pathologic features and clinical behavior. J Clin Oncol. 2006; 24:4677-84. [PubMed: 16966691]

127. Zhou L, et al. Integrated profiling of microRNAs and mRNAs: microRNAs located on Xq27.3 associate with clear cell renal cell carcinoma. PLoS One. 2010; 5:e15224. [PubMed: 21253009]

128. Zha X, et al. Lactate dehydrogenase B is critical for hyperactive mTOR-mediated tumorigenesis. Cancer Res. 2011; 71:13-8. [PubMed: 21199794]

129. Kinoshita T, et al. Tumor suppressive microRNA-375 regulates lactate dehydrogenase $B$ in maxillary sinus squamous cell carcinoma. Int J Oncol. 2012; 40:185-93. [PubMed: 21922130]

130. Pullen TJ, da Silva Xavier G, Kelsey G, Rutter GA. miR-29a and miR-29b contribute to pancreatic beta-cell-specific silencing of monocarboxylate transporter 1 (Mct1). Mol Cell Biol. 2011; 31:3182-94. [PubMed: 21646425]

131. Bode BP, Souba WW. Modulation of cellular proliferation alters glutamine transport and metabolism in human hepatoma cells. Ann Surg. 1994; 220:411-22. discussion 422-4. [PubMed: 7944654]

132. DeBerardinis RJ, Cheng T. Q's next: the diverse functions of glutamine in metabolism, cell biology and cancer. Oncogene. 2010; 29:313-24. [PubMed: 19881548] 
133. DeBerardinis RJ, et al. Beyond aerobic glycolysis: transformed cells can engage in glutamine metabolism that exceeds the requirement for protein and nucleotide synthesis. Proc Natl Acad Sci U S A. 2007; 104:19345-50. [PubMed: 18032601]

134. Zhou Q, Souba WW, Croce CM, Verne GN. MicroRNA-29a regulates intestinal membrane permeability in patients with irritable bowel syndrome. Gut. 2010; 59:775-84. [PubMed: 19951903]

135. Zhou Q, Souba WW, Croce CM, Verne GN. MicroRNA-29a regulates intestinal membrane permeability in patients with irritable bowel syndrome. Gut. 2010; 59:775-84. [PubMed: 19951903]

136. Muniyappa MK, et al. MiRNA-29a regulates the expression of numerous proteins and reduces the invasiveness and proliferation of human carcinoma cell lines. Eur J Cancer. 2009; 45:3104-18. [PubMed: 19818597]

137. Bauer DE, Hatzivassiliou G, Zhao F, Andreadis C, Thompson CB. ATP citrate lyase is an important component of cell growth and transformation. Oncogene. 2005; 24:6314-22. [PubMed: 16007201]

138. Deberardinis RJ, Lum JJ, Thompson CB. Phosphatidylinositol 3-kinase-dependent modulation of carnitine palmitoyltransferase $1 \mathrm{~A}$ expression regulates lipid metabolism during hematopoietic cell growth. J Biol Chem. 2006; 281:37372-80. [PubMed: 17030509]

139. Ali $\mathrm{S}$, et al. Gemcitabine sensitivity can be induced in pancreatic cancer cells through modulation of miR-200 and miR-21 expression by curcumin or its analogue CDF. Cancer Res. 2010; 70:3606-17. [PubMed: 20388782]

140. Khasawneh J, et al. Inflammation and mitochondrial fatty acid beta-oxidation link obesity to early tumor promotion. Proc Natl Acad Sci U S A. 2009; 106:3354-9. [PubMed: 19208810]

141. Calle EE, Rodriguez C, Walker-Thurmond K, Thun MJ. Overweight, obesity, and mortality from cancer in a prospectively studied cohort of U.S. adults. N Engl J Med. 2003; 348:1625-38. [PubMed: 12711737]

142. Michaud DS, et al. Physical activity, obesity, height, and the risk of pancreatic cancer. JAMA. 2001; 286:921-9. [PubMed: 11509056]

143. Cheon EC, et al. Alteration of strain background and a high omega- 6 fat diet induces earlier onset of pancreatic neoplasia in EL-Kras transgenic mice. Int J Cancer. 2011; 128:2783-92. [PubMed: 20725998]

144. Martinez-Outschoorn UE, et al. Oxidative stress in cancer associated fibroblasts drives tumorstroma co-evolution: A new paradigm for understanding tumor metabolism, the field effect and genomic instability in cancer cells. Cell Cycle. 2010; 9:3256-76. [PubMed: 20814239]

145. Aprelikova $\mathrm{O}$, et al. The role of miR-31 and its target gene SATB2 in cancer-associated fibroblasts. Cell Cycle. 2010; 9:4387-98. [PubMed: 20980827]

146. Enkelmann A, et al. Specific protein and miRNA patterns characterise tumour-associated fibroblasts in bladder cancer. J Cancer Res Clin Oncol. 2011; 137:751-9. [PubMed: 20607552]

147. $\mathrm{Hu} \mathrm{W}$, et al. Negative regulation of tumor suppressor p53 by microRNA miR-504. Mol Cell. 2010; 38:689-99. [PubMed: 20542001]

148. Pavlides $\mathrm{S}$, et al. The autophagic tumor stroma model of cancer: Role of oxidative stress and ketone production in fueling tumor cell metabolism. Cell Cycle. 2010; 9:3485-505. [PubMed: 20861672]

149. Preis M, et al. MicroRNA-10b Expression Correlates with Response to Neoadjuvant Therapy and Survival in Pancreatic Ductal Adenocarcinoma. Clin Cancer Res. 2011; 17:5812-21. [PubMed: 21652542]

150. Shen X, et al. Heparin impairs angiogenesis through inhibition of microRNA-10b. J Biol Chem. 2011; 286:26616-27. [PubMed: 21642433]

151. Sun L, et al. MicroRNA-10b induces glioma cell invasion by modulating MMP-14 and uPAR expression via HOXD10. Brain Res. 2011; 1389:9-18. [PubMed: 21419107]

152. Fukuda A, et al. Stat 3 and MMP7 contribute to pancreatic ductal adenocarcinoma initiation and progression. Cancer Cell. 2011; 19:441-55. [PubMed: 21481787] 
153. Ali S, Almhanna K, Chen W, Philip PA, Sarkar FH. Differentially expressed miRNAs in the plasma may provide a molecular signature for aggressive pancreatic cancer. Am J Transl Res. 2011; 3:28-47. [PubMed: 21139804]

154. Lukiw WJ, Pogue AI. Induction of specific micro RNA (miRNA) species by ROS-generating metal sulfates in primary human brain cells. J Inorg Biochem. 2007; 101:1265-9. [PubMed: 17629564]

155. Pizzimenti S, et al. MicroRNA expression changes during human leukemic HL-60 cell differentiation induced by 4-hydroxynonenal, a product of lipid peroxidation. Free Radic Biol Med. 2009; 46:282-8. [PubMed: 19022373]

156. Fuss M. Strategies of assessing and quantifying radiation treatment metabolic tumor response using F18 FDG Positron Emission Tomography (PET). Acta Oncol. 2010; 49:948-55. [PubMed: 20831482]

157. Bhardwaj V, Rizvi N, Lai MB, Lai JC, Bhushan A. Glycolytic enzyme inhibitors affect pancreatic cancer survival by modulating its signaling and energetics. Anticancer Res. 2010; 30:743-9. [PubMed: 20392992]

158. Yang H, et al. MicroRNA expression profiling in human ovarian cancer: miR-214 induces cell survival and cisplatin resistance by targeting PTEN. Cancer Res. 2008; 68:425-33. [PubMed: 18199536]

159. Ho AS, et al. Circulating miR-210 as a Novel Hypoxia Marker in Pancreatic Cancer. Transl Oncol. 2010; 3:109-13. [PubMed: 20360935]

160. Wang J, et al. MicroRNAs in plasma of pancreatic ductal adenocarcinoma patients as novel blood-based biomarkers of disease. Cancer Prev Res (Phila). 2009; 2:807-13. [PubMed: 19723895]

161. Kelly TJ, Souza AL, Clish CB, Puigserver P. A hypoxia-induced positive feedback loop promotes hypoxia-inducible factor 1alpha stability through miR-210 suppression of glycerol-3-phosphate dehydrogenase 1-like. Mol Cell Biol. 2011; 31:2696-706. [PubMed: 21555452]

162. Liu J, et al. Combination of plasma microRNAs with serum CA19-9 for early detection of pancreatic cancer. Int J Cancer. 2011

163. Ryu JK, et al. Elevated microRNA miR-21 Levels in Pancreatic Cyst Fluid Are Predictive of Mucinous Precursor Lesions of Ductal Adenocarcinoma. Pancreatology. 2011; 11:343-50. [PubMed: 21757972]

164. Morita T, Matsuzaki A, Kurokawa S, Tokue A. Forced expression of cytidine deaminase confers sensitivity to capecitabine. Oncology. 2003; 65:267-74. [PubMed: 14657601]

165. Borchert GM, Holton NW, Larson ED. Repression of human activation induced cytidine deaminase by miR-93 and miR-155. BMC Cancer. 2011; 11:347. [PubMed: 21831295] 


\section{Key Points}

> Pancreatic tumours are highly glucose dependent; the ${ }^{18}$ F-FDG-PET imaging of pancreatic tumours utilizes the propensity of pancreatic tumours to take up high amounts of glucose

- MicroRNAs (miRNAs) are linked to pancreatic cancer metabolism at two levels: first, miRNAs are regulated by metabolic activity; and second, miRNAs can directly or in directly regulate metabolic activity of pancreatic tumours

> By modulating the tumour microenvironment, miRNAs can also alter the tumourstromal metabolic interactions in pancreatic adenocarcinoma

$>$ miRNAs can differentiate the metabolic status from normal pancreas to chronic pancreatitis to pancreatic cancer

$>$ miRNAs could serve as biomarkers for the metabolic state of the tumour and may have diagnostic and therapeutic implications for pancreatic cancer 


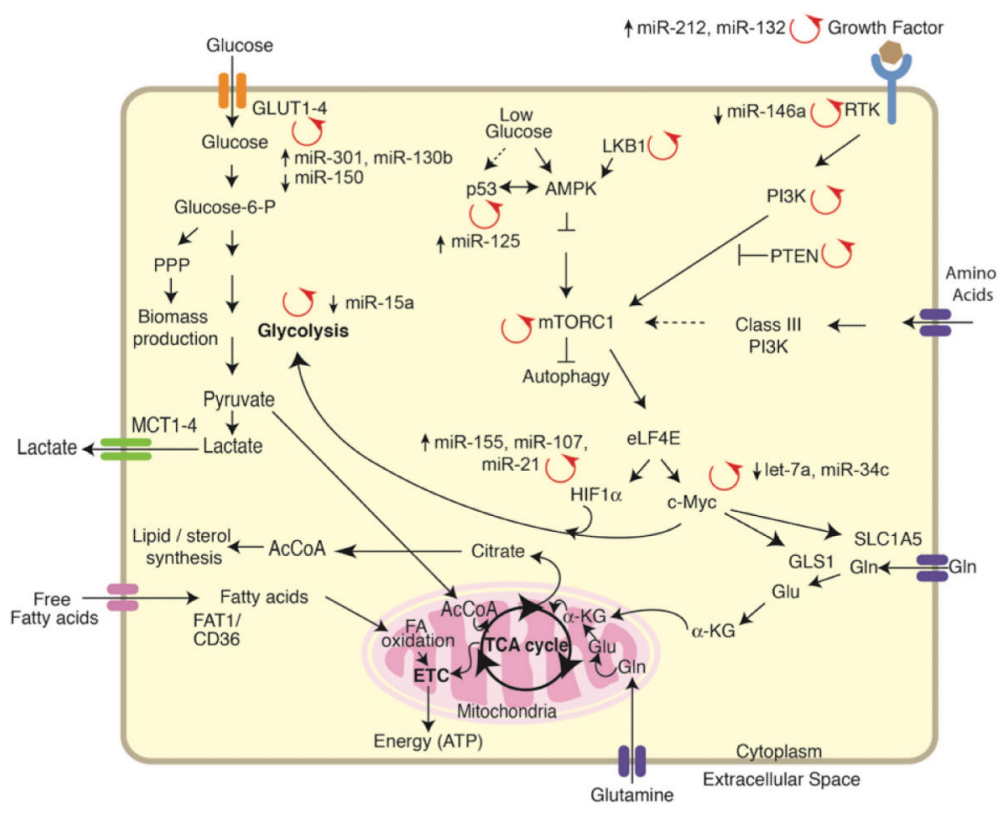

Figure 1. Modulation of metabolic machinery and its regulators by miRNAs in a pancreatic cancer cell

The steps regulated by miRNAs are indicated by red bars. Metabolites are indicated in blue. All the metabolic pathways are italicized in bold. GLUT (Glucose Transporter), PPP (Pentose Phosphate Pathway), Glucose-6-P (Glucose-6-phosphate), AcCoA (Acetyl Coenzyme A), MCT1-4 (Monocarboxylate transporter 1-4), TCA cycle (Tricarboxylic Acid cycle), FA (Fatty Acid), and ETC (Electron Transport Chain), RTK (Receptor Tyrosine Kinase), PI3K (Phosphoinositide 3 Kinase), PTEN (Phosphatase and Tensin Homolog), LKB1 (Liver Kinase B1 or Serine Threonine Kinase 11), AMPK (5' Adenosine Monophosphate-Activated Protein Kinase), mTORC1 (Mammalian Target of Rapamycin Complex1), eIF4E (eukaryotic translation Initiation Factor 4E), a-KG (alphaKetoGlutarate). 


\section{Table 1}

miRNAs and metabolic regulation in pancreatic cancer

\begin{tabular}{|c|c|c|}
\hline $\begin{array}{l}\text { Regulating/regulated } \\
\text { pathway }\end{array}$ & Upregulated & Downregulated \\
\hline \multicolumn{3}{|c|}{ Metabolic activity regulating miRNA } \\
\hline ROS & $\mathrm{miR}-155$ and $\mathrm{miR}-7 \mathrm{~b}$ & miR-7c and miR-99a \\
\hline Hypoxia & $\begin{array}{l}\mathrm{miR}-210, \mathrm{miR}-181 \mathrm{~b} \text {, and } \\
\mathrm{miR}-23 \mathrm{a} / \mathrm{b}\end{array}$ & miR-20a \\
\hline Glucose status & $\begin{array}{l}\operatorname{miR}-124, \mathrm{miR}-212, \mathrm{miR}- \\
132, \mathrm{miR}-409-3 \mathrm{p}, \mathrm{miR}-30 \mathrm{~d}, \\
\text { and } \mathrm{miR}-29 \mathrm{c}\end{array}$ & \\
\hline \multicolumn{3}{|c|}{ Regulation of metabolic activity by miRNAs } \\
\hline Glucose uptake & $\mathrm{miR}-301$ and $\mathrm{miR}-130 \mathrm{~b}$ & $\operatorname{miR}-150$ \\
\hline $\begin{array}{l}\text { Direct regulation of } \\
\text { glycolysis }\end{array}$ & & $\operatorname{miR}-15 \mathrm{a}$ \\
\hline Growth factor signalling & $\mathrm{miR}-212$ and $\mathrm{miR}-132$ & miR-146a \\
\hline p53 activity & miR-125 & \\
\hline c-Myc activity & & let-7a and miR-34c \\
\hline RAS family & $\operatorname{miR}-217$ & let-7a and miR-96 \\
\hline HIF1a activity & $\begin{array}{l}\text { miR-155, miR-107, and } \\
\text { miR-21 }\end{array}$ & \\
\hline TCA machinery & $\mathrm{miR}-210$ and $\mathrm{miR}-125 \mathrm{~b}$ & \\
\hline $\begin{array}{l}\text { Glucose flux through } \\
\text { glycolysis vs. TCA cycle }\end{array}$ & $\mathrm{miR}-103 / 107$ & \\
\hline
\end{tabular}

